\title{
Downward nominal wage flexibility- real or measurement error?
}

\author{
Peter Gottschalk*
}

March 2004

\begin{abstract}
This paper presents a new method to correct for measurement error in wage data and applies this method to address an old question. How much downward wage flexibility is there in the U.S? We apply standard methods developed by Bai and Perron (1998b) to identify structural breaks in time series data. Applying these methods to wage histories allows us to identify when each person experienced a change in nominal wages. The length of the period of constant nominal wages is left unrestricted and is allowed to differ across individuals, as is the size and direction of the nominal wage change. We apply these methods to data from the Survey of Income and Program Participation. The evidence we provide indicates that the probability of a cut in nominal wages is substantially overstated in data that is not corrected for measurement error.
\end{abstract}

*Professor of Economics, Boston College, Chestnut Hill MA 02467 gottscha@bc.edu. This project was partially funded under a grant from the Russell Sage Foundation. Jushan Bai provided valuable guidance. 


\section{Downward nominal wage flexibility real or measurement error?}

\section{Introduction}

This paper proposes a new method to answer a long standing question. How flexible are wages in the U.S? We show that the answer to this question depends crucially on whether one adjusts for measurement error since many of the reported changes in wages reflect measurement error and not real changes in nominal wages. We offer a new method for addressing the issue of measurement error and show that the application of this method leads to substantially less wage mobility than found in data that does not correct for measurement error.

Whether wages are flexible continues to be central to both theoretical and policy debates. On the theoretical side, the division between nominal contracting theories and real business cycle models revolves largely around the question of wage flexibility ${ }^{1}$. On the policy side, proponents of loosening of European labor regulations point to the lower unemployment rates in the US as a sign of the results of adopting greater wage flexibility. ${ }^{2}$

There is little disagreement that US labor markets adjust to upward pressure on wages. More contentious is the claim that wages fall freely in response to a decline in demand. While it would seem straightforward to quantify the extent of wage rigidity the extensive previous literature has not come to a consensus on this question. Studies using large nationally representative data sets, such as the Panel Study of Income Dynamics (PSID), can be cited to support either the position that wage cuts are rare or that they are common. ${ }^{3}$. Roughly seven percent of respondents working for the same employer in two interviews a year apart report the same nominal wages in both interviews. This is consistent with the view that nominal wages are sticky. However, these same studies show that roughly 17 percent of respondents experience a decline in nominal wages while working for the same employer in interviews a year apart. This implies substantial downward flexibility. Studies based on data from individual firms, however, show only two to three percent of workers experiencing nominal wage cuts, which implies substantial rigidity

A possible reconciliation of these contradictory findings is that much of the downward mobility in the PSID reflects measurement error. One suspects that studies based on

\footnotetext{
${ }^{1}$ See Kean (1993) for references to this extensive literature

${ }^{2}$ For an example of this position see OECD Job Studies (1994)

${ }^{3}$ See McClaughlin (1994), Card and Hyslop (1997), and Kahn (1997). These studies are described more extensively in the following section.
} 
self-reported wages gathered in two different interviews can lead to spurious changes in wages $^{4}$. On the other hand carefully focused studies of individual firms may show fewer cases of nominal wage cuts if they are less prone to measurement error.

The potential importance of measurement error is acknowledged by all parties using data sets such as the PSID to study nominal wage rigidity. The problem has been to find a credible identification strategy to separate the signal from the noise in reported wage data.

This paper proposes a new method for addressing the issue of measurement error and presents new evidence on the question of downward wage rigidity. Like all previous studies our method also needs to make identifying assumptions to separate the signal from the noise in reported wages. Our identifying assumption is that nominal wages adjust in discrete steps. The length of the period of constant nominal wages is unspecified and is allowed to vary across individuals, as is the size of the change in nominal wage for each individual. This set of assumptions allow us to use well developed econometric techniques for identifying structural breaks in time series data developed by Bai and Perron (1998b) to isolate changes in actual wages from changes that reflect measurement error ${ }^{5}$. If wages adjust on a yearly basis, then this will be revealed in the data by a mode around twelve months in the distribution of durations of constant wages. If wages adjust more quickly, then this will be revealed by the data.

Our empirical work, using the Survey of Income and Program Participation (SIPP), shows that the distribution of changes in reported wages, before correcting for measurement error, is similar to that found in the PSID. Roughly 17 percent of workers report a decline in nominal wages while working for the same employer. However, when we correct for measurement error we obtain results that are much closer to those found in the firm specific studies. Our estimates from a nationally representative data set indicate that between four and five percent of hourly workers actually experience a decline in nominal wages over a year period while working for the same employer. The balance reflects measurement error. This indicates that downward wage adjustments are rare, even in nationally representative data sets.

This study follows in the empirical tradition of prior studies and makes no attempt to address the tougher question of why such downward rigidity exists ${ }^{6}$. While there is still

\footnotetext{
${ }^{4}$ See Bound and Krueger (1991) and Bound et al. (1994) for a discussion of reporting error in earnings in the PSID. See Brown and Light (1992) for a discussion of reporting error in tenure which will also lead to misclassification of movers and stayers within the same firm.

${ }^{5}$ Bai and Perron (1998b) present the econometric theory, Bai and Perron (1998a) present the algorithm used to implement this estimator.

${ }^{6}$ Blinder and Choi (1990), Bewley (1999) and Hanes (2000) review potential explanations for nominal
} 
no well accepted theory of why firms and workers would chose nominal contracting, much less why such contracts should not allow for negative changes, the lack of such a theory is not evidence that such contracts do not exist. ${ }^{7}$ Whether nominal wages are rigid is an empirical question that must first be answered in order to determine whether there is a need for a theoretical explanation.

The remainder of this paper is divided into five sections. We start by reviewing the empirical literature on nominal rigidity. The following two sections present our methodology and data. Results are presented in the following section. The conclusion summarizes the findings of this study.

\section{Review of Literature}

Table 1 presents an overview of the major empirical studies of nominal rigidities in the U.S ${ }^{8}$. Since many of the studies focus on the proportion of persons reporting constant nominal wages, we show this proportion as well as the proportion reporting declines in nominal wages, which is the focus of our study. The top panel summarizes the literature based on nationally representative samples. The second panel summarizes the results of the two best know studies that focus on a particular firm or a specific geographic area ${ }^{9}$.

All of the studies in the top panel use the PSID, a large nationally representative data set that can be used to compare wages across interviews a year apart for respondents working for the same firm in both interviews. While the studies using the PSID set have different foci and different samples, they paint a similar picture. Card and Hyslop (1997) focus on the effects of inflation on the proportion of persons with rigid nominal wages. They focus on the fact that seven to ten percent of workers report the same nominal wage in two interviews a year apart as evidence of wage rigidity. Their study, however, also reports that 15 to 20 percent of respondents experienced a cut in nominal wages between interviews ${ }^{10}$. This would imply that nominal wage cuts are not rare. Kahn (1997) also examines the distribution of nominal wage changes but with a focus on the difference between hourly wage workers and salaried workers. She, likewise, finds a substantial spike at zero but an

rigidity.

${ }^{7}$ See Kean (1993) for a discussion of this point previously made by Fischer in 1977.

${ }^{8}$ While Shea (1995)'s focus is somewhat different he is also concerned with the misreporting of wage changes in the PSID. His solution to the measurement problem is to match PSID respondents to union wage contracts.

${ }^{9}$ We include only studies that provide information on the probability that a worker will experience a wage change. Studies such as Bewley (1999) and Blinder and Choi (1990) provide information on the proportion of firms in non-random data sets that cut nominal wages for some of their workers.

${ }^{10}$ See discussion of Figures 1a and 1b in Card and Hyslop (1997). 
even larger proportion of workers with nominal pay cuts ${ }^{11}$. Card and Hyslop (1997)'s and Kahn (1997)'s conclusion that the PSID offers strong evidence of wage rigidity, therefore, reflects their focus on the spike at zero rather than on the cumulative density below zero, which is large in both studies.

McClaughlin (1994), using the same data set, comes to the opposite conclusion that nominal wages show substantial downward flexibility. This is largely the result of his focusing on the full distribution, including the negative tail, rather than on the spike. He also finds that seven percent of his sample have constant nominal wages and 17 percent experience nominal wage declines, which is nearly identical to Kahn (1997). ${ }^{12}$ However, his focus on the symmetry of the whole distribution, including the density below zero, leads him to conclude that nominal wages are not rigid. While there are differences across studies, the difference in conclusions are more the result of which attribute of the distribution is emphasized than of differences in empirical results.

The fact that all these studies based on the PSID show roughly 17 percent of workers with nominal wage declines is strong evidence that nominal wages are not sticky for a large proportion of the workforce. In contrast, studies of individual firms or narrow labor markets show that nominal wage cuts are rare and occur only in extreme circumstances. Studies of specific labor markets by Akerlof et al. (1996) and specific firms by Altonji and Devereux (2000) find that nominal wage declines are rare and that the prevalence of constant wages is more than four times as high as that found in the PSID. This implies substantially rigidity. In a telephone interview of D.C. residents Akerlof et al. (1996) find that only 2.7 percent of respondents experienced a decline in nominal wages but that fully 30.8 percent had rigid wages. Likewise, Altonji and Devereux (2000) find that only .5 percent of salaried workers and 2.5 percent of hourly workers in a large financial corporation experienced nominal wage cuts. On the other hand, more than 40 percent of the sample had constant nominal wages, which is substantially more than the seven to ten percent found in the PSID. These studies, therefore, indicate substantial more nominal wage rigidity than those based on the PSID.

Almost all studies that use the PSID acknowledge the possibility of measurement error. While Altonji and Devereux (2000) relies primarily on functional form and distributional assumptions in order to identify measurement error, McClaughlin (1994), Card and Hyslop (1997) and Akerlof et al. (1996) rely on the validation studies by Bound and Krueger (1991)

\footnotetext{
${ }^{11}$ Table 1 of Kahn (1997) shows 7 percent of respondents working for the same employer with rigid wages and 18 percent with nominal pay cuts.

${ }^{12}$ McClaughlin (1994) page 385.
} 
and by Bound et al. (1994) plus auxiliary assumptions for identification. ${ }^{13}$ These validation studies give estimates of the ratio of the variance of the error component to the variance of reported wages. The proportion of the variation that is noise must then be combined with additional assumptions in order to make inferences on the proportion of persons with constant or negative wage changes. Typically these assumptions include assumptions about the proportion of workers reporting wages without error, assumptions about the functional form of the measurement error and assumptions about the autocorrelation of such errors. Assuming that the validation studies are applicable to the samples and wage measures used in studies of nominal wages and assuming that the identifying assumptions are correct, leads to consistent corrections for measurement error. However, even after these corrections are made the contradictory evidence remains and none of the authors alter their conclusions. Thus, the approach to measurement error used in these studies does not reconcile the large discrepancies in results.

\section{Methodology}

The method we use to correct for measurement error relies heavily on Bai and Perron (1998a) who develope a method for identifying structural breaks in time series data. In our case the time series is a set of wages reported by an hourly wage earner working for the same employer. Breaks occur when the unobserved wage changes. Our identifying assumption is that nominal wages are adjusted at discrete points while working for the same employer. Between these break points nominal wages are constant. Like Bai and Perron (1998a) we make no assumption about the duration between breaks or the size and direction of the changes at the break points.

As an illustration consider the following sequence of wages reported by a male hourly worker working for the same employer over a 28 month period: $\$ 16, \$ 17, \$ 16, \$ 16, \$ 18$, $\$ 19, \$ 18^{14}$. The method described is this section finds one statistically significant break between the fourth and fifth reported wages ( $\$ 16$ and $\$ 18)$. Allowing for a break between $\$ 16$ and $\$ 18$ leads to a reduction in the sum of squared errors that is sufficiently large to

\footnotetext{
${ }^{13}$ Since Bound and Krueger (1991) is a validation study of the CPS the estimates from this study requires the assumption that the form of the measurement error is the same in the PSID as in the CPS. Bound et al. (1994) explore measurement error in the PSID using detailed payroll records from a large manufacturing firm. This requires the assumption that workers in this firm had similar measurement error as sample members in the nominal wage studies. Even within a single validation study there is a wide range of estimates of the proportion of the variance in reported wages that reflects measurement error.

${ }^{14}$ This is is a the rounded sequence of reported wages for male number 410 in in his first non-left cesnsored job in the 86 panel.
} 
be statistically significant. This implies that reported wages for this individual are noisy measures of the actual wages which were constant over the first four interviews, increased between the fourth and fifth interviews, then stay at a new constant through the remaining interviews. The conclusion that actual wages increased once is very different from the conclusion based on reported wages. Based on reported wages one would conclude that the individual had experienced three wage increases and two wage cuts while working for the same employer over a little more than a two year period.

This example illustrates the importance of our identifying assumption that wages adjust at discrete points. Without this assumption it is possible that the employee indeed experienced changes in nominal hourly wage in five of the six reporting periods. Without this assumption we cannot separate measurement error from true changes in nominal wages.

We now turn to a more formal description of our method. Following Bai and Perron (1998a), let $T$ be the number of periods we observe an individual working for the same employer. Over the period there are $m$ changes in nominal wages, which occur at $T_{1}, T_{2}$, . . $T_{m}$. The observed wage at $t$ in segment $j, y_{t}$, is equal to a constant, $\beta_{j}$, plus measurement error, $u_{t}:{ }^{15}$

$$
\begin{aligned}
y_{t} & =\beta_{1}+u_{t} \ldots \ldots . t=1 \ldots T_{1} \\
& =\beta_{2}+u_{t} \ldots \ldots . t=T_{1}+1 \ldots . . T_{2} \\
& =\beta_{m+1}+u_{t} \ldots . . t=T_{m} \ldots . T
\end{aligned}
$$

The objective is to estimate the break points, $T_{1} \ldots . T_{m}$ and the $m+1 \beta_{j}$ 's that represent the constant nominal wages received in each subperiod between break points.

Bai and Perron (1998b) propose a least squares estimator of these parameters. Start by considering the case where the number of break points, $m$, is known ${ }^{16}$. The statistical problem is to find the values of $\hat{T}_{1 \ldots . .} \hat{T}_{m}$ that minimize the sum of square residuals of the observed values around the $m+1$ constants, $\beta_{1} \ldots \beta_{m+1}$. This leads to the computational problem that the number of values of $\hat{T}_{1 \ldots . .} \hat{T}_{m}$ is potentially large since there are $T-h$ possible start dates, where $h$ is the minimum possible length of a subperiod. Even after imposing the condition that end dates must be greater than the start dates plus $h$, the number of potential combinations of start and end dates can be large if $T$ is large and $m$

\footnotetext{
${ }^{15}$ The estimator proposed in Bai and Perron (1998b) requires only very weak restrictions on $u_{t}$. See assumption A4(i) of their paper.

${ }^{16}$ This assumption is introduced only to make the exposition clear. It is dropped later in the argument..
} 
is near $\frac{T}{2} 17$

Bai and Perron (1998a) show that this computational problem can be reduced to a recursive problem via a dynamic programming algorithm. The minimum sum of squared residuals over all $m$ estimated break points, $\widetilde{S S R}\left(\hat{T}_{1 \ldots . .} \hat{T}_{m}\right)$, can be written as the optimal over the first $m-1$ break points, $\widetilde{S S R}\left(\hat{T}_{1 \ldots . .} \hat{T}_{m-1}\right)$,plus the optimal over the remaining segment, $S S R\left(\hat{T}_{m}\right)$. The latter simply requires finding the $\hat{T}_{m}$ that minimizes the sum of squared residuals in the remaining segment:

$$
\widetilde{S S R}\left(\hat{T}_{1 \ldots . .} \hat{T}_{m}\right)=S S R\left(\hat{T}_{1 \ldots . .} \hat{T}_{m-1}\right)+\min _{\hat{T}_{m}} S S R\left(\hat{T}_{m}\right)
$$

This algorithm is solved recursively, which leads to the following procedure. Calculate the $S S R$ for the $T-2 h$ possible breaks that divide the $T$ observations into two segments of minimum length $h$. Pick the break point with the minimum $S S R$ among these $T-2 h$ break points. Take the two remaining segments and repeat the procedure until there are $m$ segments. This will yield the minimum $S S R$ over all possible combinations of the $m$ breaks with resulting segments of minimum length $h$.

Thus far $m$ has been taken as given. Since the number of breaks is not generally known, it must also be estimated. This again proceeds sequentially. Start by partitioning the $T$ observations into two segments. Test the null of no structural break, which is an appropriate $F$ test of the $S S R$ with and without the break. If the null is rejected divide the resulting two segments and again test the null of no structural break within each of these subsegments. Continue subdividing until the null cannot be rejected. The resulting break points occur where the change in mean wages within each segment is sufficiently large compared to the within segment variation around each mean that one can reject the null that the difference in means reflects measurement error. The average $y_{t}$ over the $j t h$ segment yields the estimate of the constant nominal wage over the segment, $\beta_{j}$, which is the object of interest.

Bai and Perron (1998b) show that the asyptotic properties of this procedure hold for a very general form of measurement error. Since our wage series are short our tests for structural breaks use small sample critical values that allow for an $A R(1)$ process in measurement error.

One major limitation of our method is the possibility that the power of the test for structural breaks in finite samples may be sufficiently low that we fail to accept structural breaks when they have occurred. This would lead to an overstatement of wage stability.

\footnotetext{
${ }^{17}$ The number of possible break points is small when $m$ is small or when it is large compared to $T$. If $m=T-1$ and $h=1$ then there is only one way of fitting $m$ breaks. If $m=1$ there are $T-1$ possible break points.
} 
Since the power of the test depends on the unobserved variance of the measurement error relative to the size of the break we offer suggestive evidence about the importance of this problem in section 5.2.2. ${ }^{18}$

\section{Data}

We use the 1986-1993 panels of the Survey of Income and Program Participation (SIPP) to measure changes in nominal wages while working for the same employer ${ }^{19}$. Each SIPP panel consists of a series of nationally representative longitudinal surveys of nearly 30,000 individuals who are followed for 24 to 40 months, depending on the panel. A new panel was started in every year other than 1989.

The primary advantage of the SIPP for our purposes is that it provides high frequency data that can be used to identify the measurement error component in reported nominal wages. This data set, however, has additional advantages over the PSID, the primary data source used in previous studies. The wage and employer data in the PSID are both problematic since they are based on information gathered in annual interviews on the wages and tenure of heads and wives. If a job change occurs some time during the year then wages computed from annual earnings and hours are mixtures of the wages on the new and the old $\mathrm{jobs}^{20}$. The alternative is to use the wage rate at the time of the PSID interview ${ }^{21}$. With annual interviews, however, it is then not possible to obtain wage changes for jobs that last less than a year.

Identifying whether a job change has taken place between interviews is also problematic since turnover in the PSID is determined by comparing the time between interviews with reported tenure on the current job. As Brown and Light (1992) has shown, the tenure questions have changed over time and contain substantial measurement error.

The SIPP avoids these problems by including the key variables necessary to identify when respondents change jobs and the wages they receive from each employer. During each interview, respondents are asked detailed questions on employer and wage histories

\footnotetext{
${ }^{18}$ In order to increase the power of our test for a significant break uses a .10 significance level, rather than the more restrictive .05 significance level which would reduce the power of the test.

${ }^{19} \mathrm{We}$ do not use the 1984 and 85 panels because of potential miscoding of employer identification numbers, which is a key variable used in this study to determine if the person is still working for the same employer.

${ }^{20}$ Even if the respondent is in the same job at two interviews, the wage rate calculated in the earlier year will be a mixture of two jobs unless the person was in the same job for the full year prior to the interview.

${ }^{21}$ The wage rate of the head is available starting in 1970 for heads paid by the hour. The same variable is available for wives in 1976 and in all years starting in 1979.
} 
that cover the previous four months. Unique codes are assigned to each employer allowing us to identify when respondents change employers. Wage rates are reported directly by hourly workers.

Our primary analysis uses wage and employer information for the month in which the interview is administered. Since the interviews take place every four months this gives us three observations on wages and employers in each year. We use this data instead of the monthly wage and employer information available in the SIPP since monthly data suffer from the well documented seam bias problem. ${ }^{22}$

While the primary focus of our study is on the wages reported for the month of interview we also use the monthly wage data in one section of the paper where we examine whether wage changes tend to occur 12 months after the previous wage change. For this part of the analysis we generate finite sample critical values to take account of seam bias problem in the SIPP. ${ }^{23}$

Our sample includes males and females not in school with positive weights who were 18 to 55 at some point during the panel. Like several earlier studies we include only hourly workers since it is well known that imputing wages by dividing earnings by hours leads to substantial measurement error. By focusing on hourly workers we, therefore, minimize the role of measurement error. All nominal wage changes are within job wage changes, defined as changes while working for the same employer.

We identify statistically significant structural breaks for each job and estimate the constant nominal wage between these breaks by calculating the average reported wage between breaks. These are referred to as adjusted wages in order to distinguish these wages purged of measurement error from the reported wages which include measurement error.

Table 2 provides descriptive statistics for our sample. The top panel shows the characteristics of the 21,406 male and 21,940 female hourly workers in the 1986-1993 SIPP panels. These workers are relatively young with a mean age in their early 30's. Not unexpectedly, our sample of hourly workers tend to have lower completed education than the population of all workers. The bottom panel shows that in our sample the average nominal 1995 wage

\footnotetext{
${ }^{22}$ Respondents are more likely to report a change in wages or employers between the last month of an interview and the first month of the next interview than between months covered in either interview. Changes, therefore, tend to occur at "seams" between interviews.

${ }^{23}$ For this part of the analysis we use the SIPP data to obtain the standard deviation of wages within and between waves in order to simulate data that has the same structure as the SIPP. We then simulate reported nominal wages for 1000 individuals without structural breaks (i.e. no change in nominal wages). These histories are then used to find the $F$ values which are exceeded ten percent of the time . These yield the finite sample critical $F$ values.
} 
for jobs held by males and females are $\$ 11.69$ and $\$ 9.36$ respectively. ${ }^{24}$ There is, however, considerable heterogeneity. The tenth and ninetieth percentiles of these two distributions are $\$ 6.09$ and $\$ 18.21$ for males and $\$ 5.12$ and $\$ 15.77$ for females. Finally, these jobs have modest growth in reported nominal wages with the mean yearly wage growth of .042 for males and .047 for females.

\section{Results}

We start by using the SIPP to mimic the PSID by comparing reported wages in interviews a year apart. This allows us to see whether the SIPP gives results similar to the PSID when similar wage measures and reporting periods are used. We then explore the importance of measurement error by contrasting reported and adjusted wages a year apart. This is followed by an analysis of the wage histories based on reported and adjusted wages in each interview.

\subsection{Comparison with PSID}

In this section we verify that when the SIPP is used to replicate the PSID we obtain results that are similar to the results in the PSID studies summarized in Table 1. Since the PSID is based on yearly interviews we measure the change in reported wages in the SIPP using wage reports a year apart for persons who are working for the same employer in both interviews.

Figure 1 shows the kernal smoothed distribution of reported changes in wages between yearly interviews for males and females. We plot the inner ninety percent of the frequency distribution since inclusion of the top and bottom five percent leads to a severe compression of the inner ninety percent which obscures the necessary detail. All summary statistics in the text are, however, for the full distribution.

Three features stand out. First, there is a large spike at zero, just as in the previous studies based on the PSID. Nearly a quarter of hourly workers have the same wage rate as in the previous interview. The second important feature of the distribution is that the mass at zero seems to be the result of taking a symmetric distribution and "sweeping-up" some of the density below zero. This is consistent with Card and Hyslop (1997) who focus on this aspect of the distribution. The third key feature of the distribution is that the cumulative density below zero is large in the SIPP, as well as in the PSID. Among

\footnotetext{
${ }^{24}$ The average nominal wage is shown for only the more recent year since averaging nominal wages across all years would not be informative.
} 
respondents reporting an hourly wage rate, 15.7 percent of males and 13.6 percent of females report lower wages than they reported a year earlier. This is similar to studies using the PSID. This confirms that these two data sets give similar results when treated in the same way.

\subsection{Role of Measurement Error}

We now assess the role of measurement error using the methodology described in section 3. For each within job wage history we first determine the statistically significant breaks in reported wages using observations across all interviews while working for the same employer. ${ }^{25}$ We then estimate the constant wage between breaks by the average of the wages reported at each of these. Under our identifying assumptions this series of adjusted wages, which changes only at the break points, is purged of measurement error. ${ }^{26}$

In order to stay as close as possible to the previous literature we begin by comparing changes in adjusted and reported wages a year apart ${ }^{27}$. We then turn to changes between each interview in the following section.

\subsubsection{Annual Changes in Reported and Adjusted Wages}

Table 3 shows the variance and the percentiles of yearly changes in reported and adjusted wages. ${ }^{28}$ The correction for measurement error reduces the variance in male wage changes from .033 for reported wages to .013 for adjusted wages. For females the reduction in variance from eliminating measurement error is nearly as large (.029 to .013). While it is not surprising that the variance of the change in adjusted wages is smaller than the variance of the change in reported wages, the reduction by more than a factor of two is quantitatively important.

The difference in dispersion is a result of differences throughout the distributions as indicated by the percentiles of the two distributions shown in the remaining rows of Table 3. The median change in reported wages among males is .025 while for adjusted wages it is zero. In fact, the year to year change in adjusted wages is zero at the twenty fifth percentile

\footnotetext{
${ }^{25}$ For expositional ease we use job and employer history interchangeably to mean an uninterrupted employment spell working for the same employer.

${ }^{26} \mathrm{By}$ construction the two series have the same growth in mean nominal wages across years. This is a result of the mean adjusted wage being equal to the mean reported wage within each segment between breaks. Since the mean adjusted and mean reported wages in each job are weighted averages across these segments, the two averages must also be equal.

${ }^{27}$ We use the reported wages and adjusted wages in the the month of the first interview and each subsequent interview one year later.

${ }^{28}$ For reported wages these are the percentiles of the distributions in Figure 1.
} 
for both males and females. This indicates that there is substantial downward rigidity. This rigidity is, however, not immutable since the $P_{01}$ for adjusted wages is -.182 for males and -.175 for females, indicating that one percent of workers experienced a reduction in nominal wages greater than fifteen percent even after adjusting for measurement error. This is, however, in stark contrast to the size of the $P_{01}$ for reported wages which is -.336 for males and -.349 for females, indicating wage cuts of over a third. At the other extreme of the distributions the differences between the two measures are smaller. The $P_{99}$ of reported wages is .457 for males and .480 for females, implying that one percent of males and females had increases in reported wages greater than 45 percent over a year period. When adjusted wages are used instead of reported wages the $P_{99}$ is smaller but still large (.358 and .369 for males and females).

Another way of looking at these distributions is to tabulate the proportion of the changes that are negative, zero and positive. This approach, shown in Table 4, allows us to compare our results directly with those found in previous studies. The first thing to note is that our correction for measurement error greatly reduces the incidence of declines in nominal wages. The top row of Table 4 shows that 15.7 percent of male hourly workers report a lower wage than a year earlier, even though they are still working for the same employer. This is reduced by a factor of three to 5.1 percent after adjusting for measurement error. The corresponding figures for females are 13.6 percent for reported wages and 4.3 percent for adjusted wages. Roughly half of males and females have the same adjusted wages as a year earlier. Some may experience a change in adjusted wages a few months later but after 12 months they still have the same wage.

Thus, correcting for measurement error reconciles much of the difference between the PSID studies and the specialized studies discussed earlier. Our finding that 5.1 percent of hourly male workers in all industries have lower wages than a year earlier is somewhat higher than that found in Akerlof et al. (1996) and in Altonji and Devereux (2000). However, it is still only a third as high as the proportion found in the PSID. Thus, the inconsistency between nationally representative data sets and specialized data sets is largely resolved by our correction for measurement error.

\subsubsection{Power}

As discussed earlier, the power of the tests for changes in wages depends on the unobserved amount of measurement error compared to the size of the change in wages. If wages are reported with a sufficiently large measurement error and the change in wages is sufficiently small our test will fail to identify this change 
The high proportion of persons classified as having constant adjusted wages in Table 4 and the relatively small proportion with increases in adjusted wages may reflect low power of the test used to determine statistically significant breaks in nominal wages. ${ }^{29}$ In order to explore the importance of this factor we proceed in two steps. First, we obtain the small sample power of the test by simulating wage data with structural breaks. Since the power of the test depends on the size of the wage change relative to the measurement error, we repeat the simulations for structural breaks of different sizes as measured by the variance of measurement error relative to the total variance, $\frac{\sigma_{u}^{2}}{\sigma_{y}^{2}}$. This ratio is not know, so we use a range of estimates based on previous studies summarized in Bound et al. (2001). Based on this literature we use values ranging between .20 and $.30^{30}$.

The second step requires that we adjust the estimates of the proportion persons with wage changes shown in Table 4 for type I and type II errors. Since the adjusted wage changes are constructed using a 10 percent significance level, this implies that the null of no change will be incorrectly rejected ten percent of the time. We, therefore, reclassify ten percent of the declines and ten percent of the increases in adjusted wages into the category of no change in adjusted wages. This adjustment, which results in an increase in the proportion of persons with constant nominal wages, is offset by the correction for type II errors. To take account of the affect of accepting the null of no change when it is false, we reclassify a proportion of the zeros. The proportion of such reclassifications depends on the power of the test, which itself depends on $\frac{\sigma_{u}^{2}}{\sigma_{y}^{2}}$.

Table 5 shows the proportion of workers with a decline, no change or increase in adjusted wages after adjusting for both type I and type II errors. Column 1 shows that when the variance of measurement error is twenty percent of the variance of reported wages, then the power of the test is .891. Since the resulting probability of a Type II

\footnotetext{
${ }^{29}$ An alternative explanation is that our sample of hourly workers in all industries includes a greater proportion of workers with little chance for advancement than that found in large firms, such as in the Altonji and Devereux (2000) sample.

${ }^{30}$ While Coder and Scoon-Rogers (1996) compares annual earnings in the SIPP with the CPS and National Income and Product accounts, there are no validation studies of changes in wage rates for hourly workers in the SIPP. The study that comes closest to our needs is Bound et al. (1994) which compares the payroll data reported by a large manufacturing plant for its hourly workers with the answers to PSID questions administered to the same workers Table 2 of their paper reports a value of .263 for $\frac{\sigma_{u}^{2}}{\sigma_{y}^{2}}$. As Bound et al. (2001) argue, this ratio for a single firm is likely to be an over estimate of proportion of the variation attributable to measurement error in a nationally representative data set. The size of the ratio reflects the small variation in wage growth in this highly unionized firm, which inflates the denominator, rather than large variation in measurement error. Since there is likely be substantially smaller variation in wage growth in a single firm than in a nationally representative sample, the measurement error ratio is likely to be substantially smaller in the PSID or the SIPP than in this firm. We,therefore, use .30 as an upper bound.
} 
error is close to the probability of a Type I error, and since these two types of errors have opposite impacts on the probability of a decline in wages, the proportions in column 1 of Table 5 are close to those in column 1 of Table 4 ( the probability of a wage decline is .051 versus.058 for males and .046 versus .043 for females ).

As the measurement error variance increases the probability that an actual change in wages will not be captured by our method increases.. As a result, the probability of both decreases and increases in wages will be higher than in Table 4 . When the error variance increases to 30 percent of total variance (column 3) the power of the test for a structural break decreases to .683 . As a result of adjusting for lower power, column 3 shows that the probability of a decline in wages increases to .080 for males and .066 for females. This is substantially higher than found in Akerlof et al. (1996) but still less than half of value found by previous studies using the PSID. Using the intermediate value for the error variance of .25 , which is closest to the value found in the validation study discussed earlier, implies that .069 of males and .056 of females experienced a decline in nominal wages. This indicates that even after correcting for power we still show that the probability of a wage decline is overstated by a factor of two when based on reported wages.

\subsection{Changes in Reported and Adjusted Wages across Interviews}

In order to be comparable to the PSID we have focused on within job changes in nominal wages at surveys a year apart. This, however, requires that the respondent stay in the same job at least a year. It also does not make the distinction between persons who will experience a change in nominal wages shortly after the yearly interview and those who will continue to earn the same nominal wage over a protracted period. In this section we, therefore, depart from previous studies by describing the size and timing of changes in nominal wages across interviews which occur every four month..

Table 6 shows the distribution of changes in nominal wages across interviews. Again reported wages show substantially more downward mobility than adjusted wages. Based on reported wages, a random male would have a .200 probability of experiencing a decline in nominal wages over a four month period. Adjusting for measurement error reduces the probability of a nominal wage cut by a factor of ten. Males have a .020 probability of having a lower wage than four months earlier. For females the probability drops from .180 to .015 after adjusting for measurement error. This is even larger than we found in the yearly probabilities shown in Table 4 . We conclude that the importance of correcting for measurement error has an even larger impact when we include jobs that last less than a 
year and allow for wage changes that occur after more than one year.

\subsection{Duration between Nominal Wage Changes}

The monthly series on reported wages in the SIPP can also be used to estimate the length of time between nominal wage adjustments. This allows us to explore the implicit assumption made in much of the literature that institutional wage setting leads to wage adjustments roughly twelve months apart. If wages are adjusted on a yearly basis for a substantial proportion of the population then this would imply that the hazard of a change in nominal wages would be low during the first few months after the start of a job or after the most recent wage adjustment. The hazard would peak around 12 months and would then decline.

To explore this hypothesis we first apply our method to adjust for measurement error in the monthly data. ${ }^{31}$ We then use the reported and adjusted monthly wage series to estimate descriptive Cox proportional hazards models in which an exit is defined as a change wages using each of these measures. ${ }^{32}$ The start of a spell occurs either when a person starts a job with a new employer or directly after experiencing a change in wages. The sample includes all non-left censored spells of constant wages while working for the same employer ${ }^{33}$. We control for age, race, a set of education dummies, a set of year dummies, and whether the month occurs at a seam between two interviews. We then recover the baseline hazards in order to examine the timing of nominal wage changes.

Figures 2 and 3 plot the baseline hazards of nominal wage changes using reported and adjusted wages respectively. We plot the cumulative hazards over three month periods in order to smooth the series, though the hazards are estimated monthly. Since our focus is on whether wages adjust on a yearly basis we construct these segments so that one segment includes the 11 th, 12 th, and 13 th months. ${ }^{34}$

Figure 2 plots the baseline hazard for a change in reported wages. When reported wages are used to define spells of constant wages we find that the highest probability of a change in reported wages occurs in the first four months since the start of a job (or since the previous change in wages.) More than half of all respondents report a wage change in

\footnotetext{
${ }^{31}$ As described earlier we generate finite sample critical values using simulated data that has the same structure as the monthly SIPP data.

${ }^{32}$ Since job duration is very likely to depend on whether a wage change has occurred, these descriptive data only show the conditional hazard of experiencing a wage change for persons still working for the same employer. Inferences cannot be made to a wider population.

${ }^{33}$ Spells are right censored when the respondent leaves the current employer.

${ }^{34}$ These intervals are centered at $3,6,9,12,15,18,21$ and 24 months. In order not to drop the hazard in the first month the first segment includes the first four months. All other segments include three months
} 
the first four months. Furthermore, the twelfth month, plays no special role as the hazard declines monotonically through all durations.

In contrast Figure 3, which shows that the hazard of a change in adjusted wages, increases during the first nine months and peaks in the segment that includes the 12th month. While the plots smooth across observations the monthly hazards (not shown) spike sharply at 12 months. The modal month for a wage change is the twelfth month, confirming that wage changes are most common a year after the last change.

Delayed wage changes are, however, not uncommon. The hazard of obtaining a wage change between the 14th and 16th month is roughly half as large as the hazard of a wage change between the 11 th and 13 th months. This indicates that the concentration of nominal wage changes at zero in the distribution of yearly wage changes, used in previous studies partially reflects spells of constant wages that will end in a few months. While the hazards continue to decline, they are still greater than zero after two years, indicating that a small proportion of the population continues to work for the same employer while receiving the same nominal wage over a protracted period.

This data can also be used to examine whether jobs that have fixed adjusted wages for 12 months are more likely than other jobs to repeat this pattern For this analysis we classify jobs on the basis of the duration of their first period of constant wages and then examine the hazard of subsequent wage changes for jobs that had a wage change in the 11 th to 13 th month. The results are presented in Figure 4. For jobs that had a wage change in the 11 th to 13 th months, the hazard again peaks in months 11 to 13 . This

indicates that our measure of wages adjusted for measurement error is consistent with a subset of jobs that regularly change wages every year. Interestingly, jobs with shorter or longer periods of initial fixed wages do not exhibit the same spike around 12 months in subsequent spells.

The fact that adjusted wage changes tend to occur roughly one year after the previous wage change (or one year after the start of the job) for a subset of jobs and that this pattern is repeated in subsequent wage spells in these jobs is consistent with the view that institutional wage setting tends to lead to wage adjustments roughly a year apart. For those who have strong priors about the timing of wage changes this offers corroborating evidence that our method captures useful information.

\subsubsection{Shifts in the hazard}

While the narrow focus of this study has been on the role of measurement error on estimates of wage rigidity, the techniques developed to answer this descriptive question can 
also be applied to more ambitious studies that attempt to estimate multivariate relationships. While the previous section has shown that our correction for measurement error changes the timing of wage changes this does not necessarily imply that our correction for measurement error has an effect on the relationship between the hazard of a wage change and observed covariates which are often the principle object of interest ${ }^{35}$. This section, therefore, focuses on the effects of correcting for measurement error on shifts in the hazard As an illustration we focus on the effects of a set of demographic characteristics and inflation on the hazard of a decline in nominal wages.

Our approach is to again estimate Cox proportional hazard models on both declines in reported wages and declines in adjusted wages to see if our method for dealing with measurement error has an effect on estimated coefficients as well as on the timing of exits.

We can use our adjusted wage series to classify changes in reported wages as either being "real" changes or "spurious" changes. The former are those changes in reported wages that are confirmed by a change in adjusted wages. "Spurious" changes are those changes in reported wages that occur when adjusted wages do not change. ${ }^{36}$

Table 7 presents the results of estimating Cox proportional hazard models of the effects of a set of demographic characteristics and inflation on the hazard of a cut in nominal wages Columns 1 to 3 are for males while columns 4 to 6 are for females. The first column for each gender shows the coefficients when an exit is defined in terms of a decline in reported wages. Columns 2 and 5 define an exit as a decline in adjusted wages. Columns 3 and 6 present results for those exits which our method identifies as "spurious" changes in wages (those in which reported wages decline but adjusted wages do not decline).

The estimated coefficients for both males and females indicate that the adjustments for measurement error have a substantial effect on estimated coefficients. Based on reported wages (shown in columns 1 and 4), one would conclude that both race and education have a statistically significant affect on the probability of a wage cut. One would conclude that white non-Hispanics are less likely to experience a cut in wages than are Hispanics and non-whites. The coefficients on education indicate that male college graduates and male high school dropouts have a lower probability of experiencing a cut in wages than do

\footnotetext{
${ }^{35}$ Since our method of correcting for measurement error does not use any information on covariates, there is no mechanical built in correlation between changes in adjusted wages and observed characteristics.

${ }^{36}$ One should, bear in mind that some of these "spurious" changes reflect type II errors in our tests for structural breaks in wages. In the extreme if our test had very little power in identifying structural breaks these "spurious" changes.would behave very similiarly to the changes in adjusted wages. Therefore, comparing the patterns in "spurious" wage changes gives indirect evidence on the power of our method to identify real changes in wages.
} 
male high school graduates. This is, however, the opposite of the result for females which shows college dropouts and college graduates having significantly higher hazards of a cut in reported wages than high school graduates.

The coefficients on demographic variables are very different when we turn to columns 2 and 5 which show the effects of demographic variables on the hazard of a decline in adjusted wages . These results show no significant differences across education groups in the hazard of a decline in wages. Columns 3 and 6 show that the education differences in reported wages are largely reflective of differences by education in the hazard of having a "spurious" decline in reported wages

Turning to the coefficients on inflation shows that nominal wage cuts, as measured by a decrease in adjusted wages, is significantly less likely to occur during periods of inflation. This is consistent with Card and Hyslop (1997) who argue that inflation greases the wheels of wage adjustment by allowing real wages to be eroded rather than requiring firms to cut nominal wages. This relationship between nominal wage cuts and inflation is statistically significant for females but not for males. Interestingly there is no relationship between inflation and "spurious" changes in wages (columns 3 and 6) either for males or for females, indicating that measurement error does not change in inflationary periods.

The results in this section illustrate that our approach to measurement error can have implications on estimates of multivariate relationships. While our focus has been primarily in describing the effects of measurement error on the marginal distribution of wage changes, the method has potentially important implications for more ambitious studies based on multivariate models.

\section{Conclusion}

It has long been recognized that measurement error may lead persons with constant wages to report different wages in two interviews, leading to an overstatement of the amount of wage flexibility.. The problem has been to find a way to separate the impact of measurement error from the impact of true changes in wages. This study offers a new method for dealing with this problem. Our method, based on methods for estimating structural breaks in time series data by Bai and Perron (1998b), relies on relatively weak identifying assumptions and makes use of the individual's full wage history in order to separate the signal from the noise.

We find that correcting for measurement error leads to substantially fewer cases of cuts in nominal wages. Tabulations of the PSID and of the SIPP show roughly 17 percent of 
persons with lower reported nominal wages in one interview than the wage reported one year earlier. Once we correct for measurement error we find that reported wages overstate the amount of downward wage flexibility by roughly a factor of three. The probability of a nominal wage cut for our sample of workers paid by the hour is .05 for males and .04 percent for females.

Since actual wages are not observable any correction for measurement error must rely on identifying assumptions that are not testable. Our assumption that wages adjust in discrete steps rather than adjusting continuously is a necessary assumption for our method. While we allow the direction of the wage changes and the spacing between wage adjustments to be determined by the data it is possible that wages do adjust continuously and that our identifying assumption is wrong. Another potential weakness of our approach is that small wage changes go undetected if the measurement error is large. Llack of power may lead us to understate the degree to which wages are flexible. Since the signal to noise ratio for our sample is unobservable this cannot be tested. We, however, show that using a range of estimates from other studies leads to modest increases in the proportion of estimated wage changes. While this is a potentially important caveat we believe that we have shown that the amount of downward mobility in reported wages overstates the amount of true downward mobility by a factor of two to three. 


\section{References}

Akerlof, G. A., Dickens, W., Perry, G., 1996. The macroeconomics of low inflation. Brookings Papers on Economic Activity 1996 (1), 1-59.

Altonji, J. G., Devereux, P. J., 2000. The extent and consequences of downward nominal wage rigidity. Research and Labor Economics 19, 383-431.

Bai, J., Perron, P., 1998a. Computation and analysis of multiple structure change models. Boston College Department of Economics Working Paper .

Bai, J., Perron, P., 1998b. Estimating and testing linear models with multiple structural changes. Econometrica 66 (1), 47-78.

Bewley, T. F., 1999. Why Wages Don’t Fall During A Recession. Harvard University Press.

Blinder, A. S., Choi, D. H., 1990. A shred of evidence on theories of wage stickiness. The Quarterly Journal of Economics 105 (3), 1003-1015.

Bound, J., Brown, C., Duncan, G., Rodgers, W., 1994. Evidence on the validity of crosssectional and longitudinal labor market data. Journal of Labor Economics 2 (2), 345-368.

Bound, J., Brown, C., Mathiowitz, N., 2001. Measurment error in survey data. In: Heckman, J., Leamer, E. (Eds.), Handbook of Econometrics. Elsevier Science B.V., Ch. 59, pp. 3707-3745.

Bound, J., Krueger, A., 1991. The extent of measurement error in longitudinal earnings data: Do two wrongs make a right? Journal of Labor Economics 9 (1), 1-24.

Brown, J., Light, A., 1992. Interpreting panel data on job tenure. Journal of Labor Economics 10 (3), 219-257.

Card, D., Hyslop, D., 1997. Does inflation 'grease the wheels of the labor market'. In: Romer, C., Romer, D. (Eds.), Reducing Inflation: Motivation and Strategy. University of Chicago Press, Chicago, Ch. 2, pp. 179-183.

Coder, J., Scoon-Rogers, L., 1996. Evaluating the quality of income data collected in the annual supplement to the march current population survey and the survey of income and program participation, working Paper, Bureau of the Census Department of Commerce - Household and Economic Statistics Division. 
Hanes, C., 2000. Nominal wage rigidity and industry characteristics in the downturns of 1893, 1929, and 1981. American Economic Review 90 (5), 1432-1446.

Kahn, S., 1997. Evidence of nominal wage stickiness from microdata. The American Economic Review 87 (5), 993-1008.

Kean, M. P., 1993. Nominal-contracting theories of unemployment: Evidence from panel data. The American Economic Review 83 (4), 932-952.

McClaughlin, K. J., 1994. Rigid wages? Journal of Monetary Economics 34 (3), 383-414.

Shea, J., March 1995. Union contracts and the life-cycle/permanent-income hypothesis. The American Economic Review 85 (1), 186-200. 
Figure 1

Kernal Smoothed Distribution of Percentage Changes

in Reported Wages

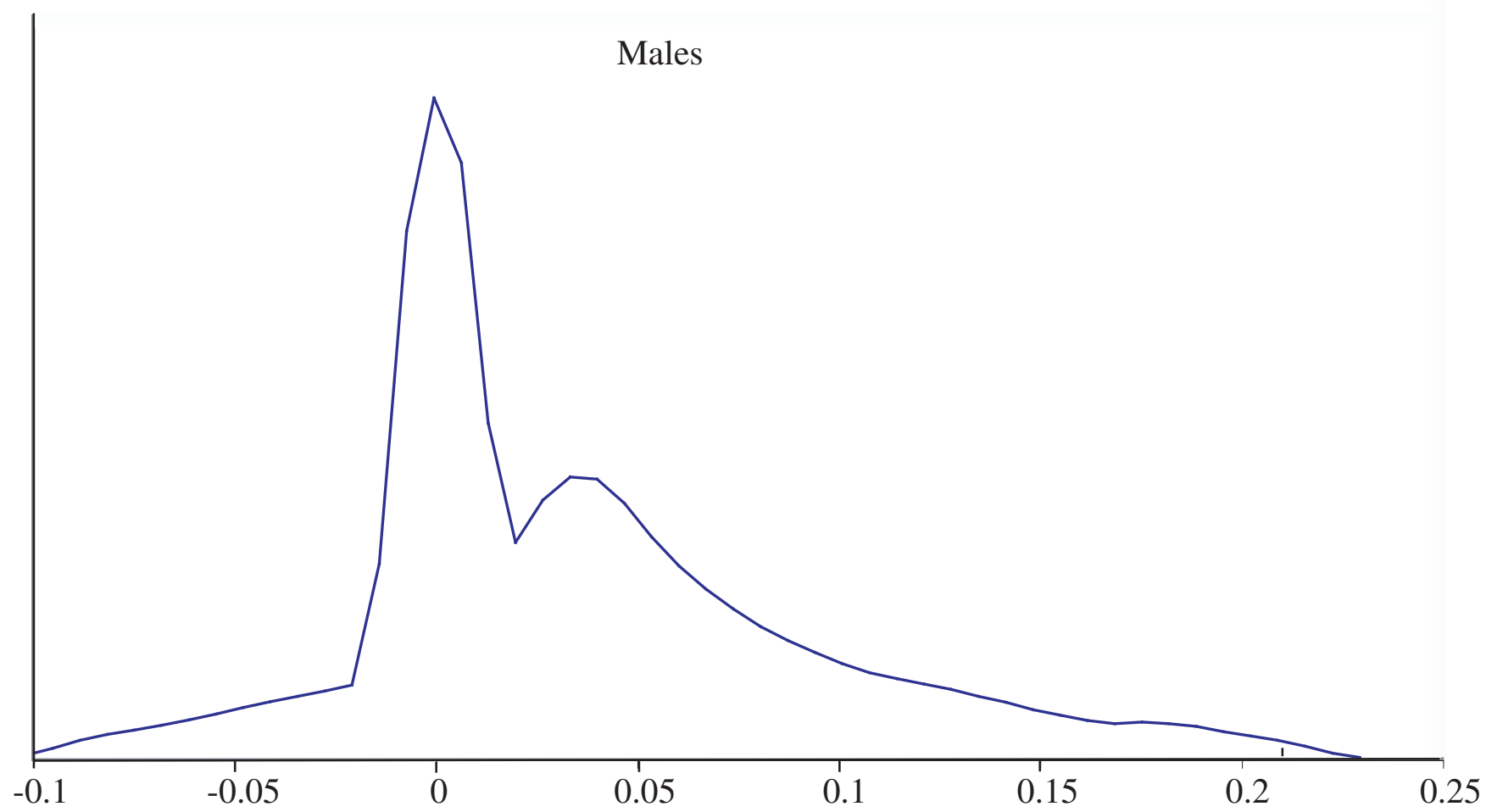

Females

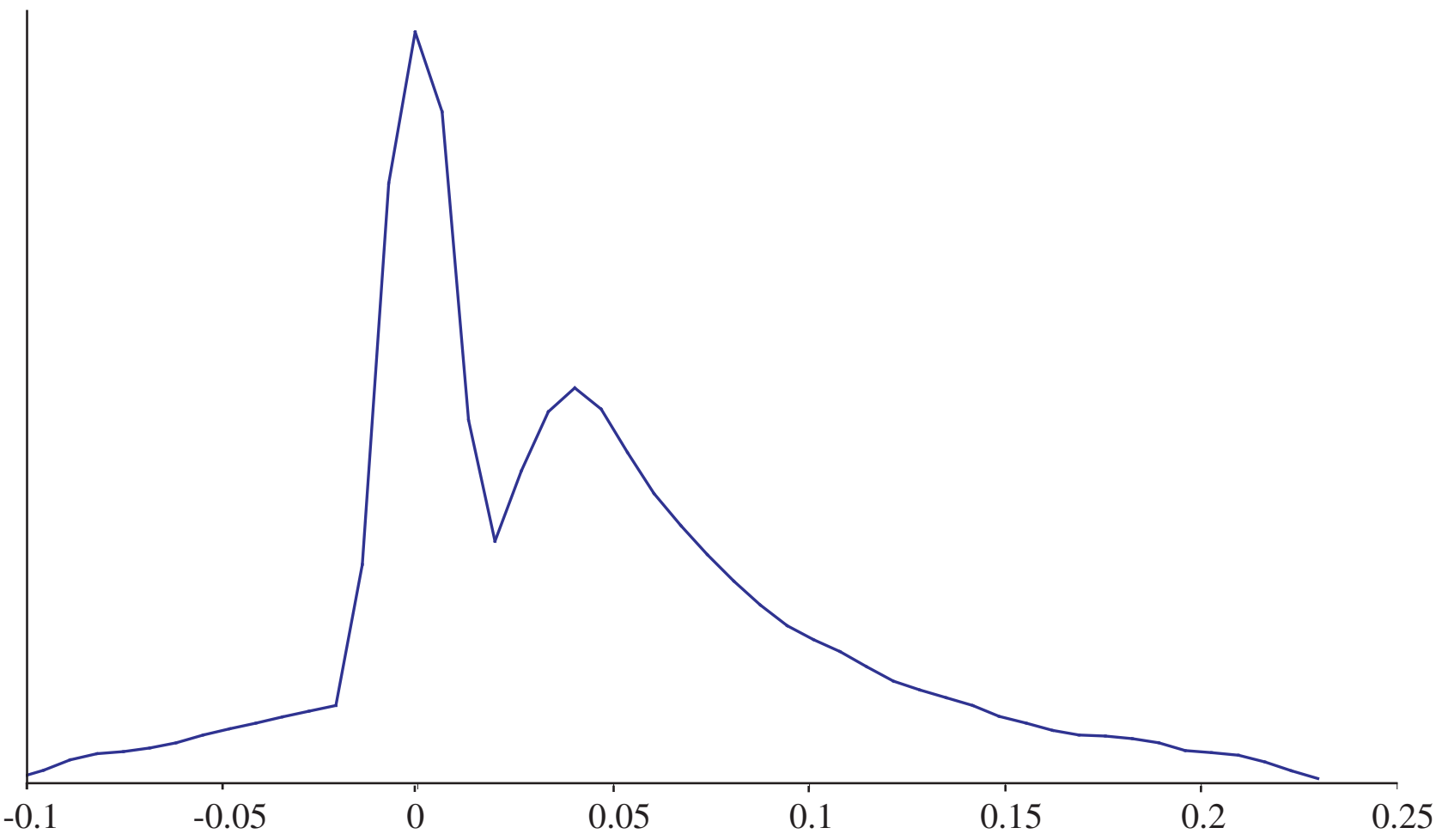


Figure 2 -- Baseline Hazard of Change in Reported Wage

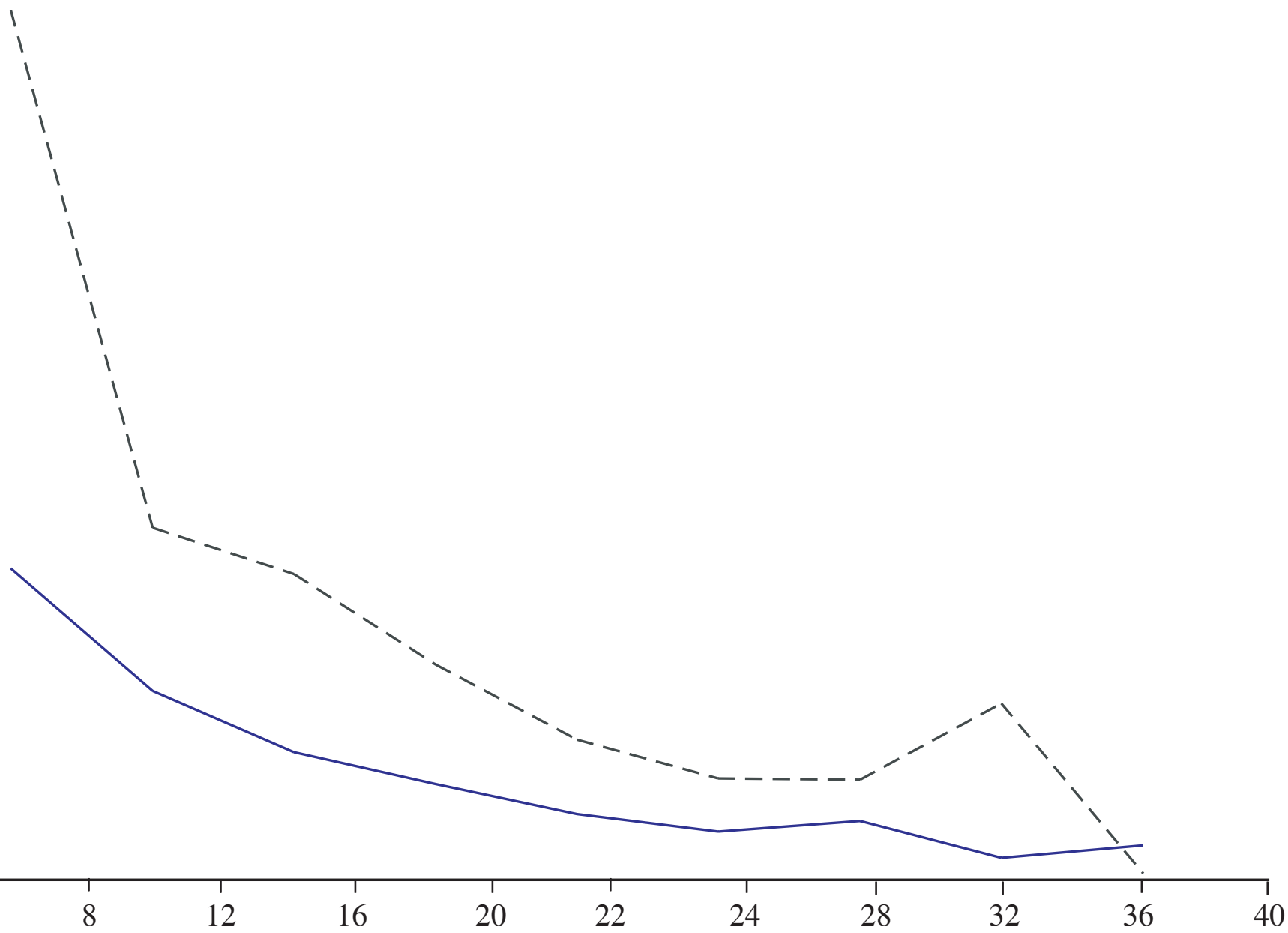

duration 


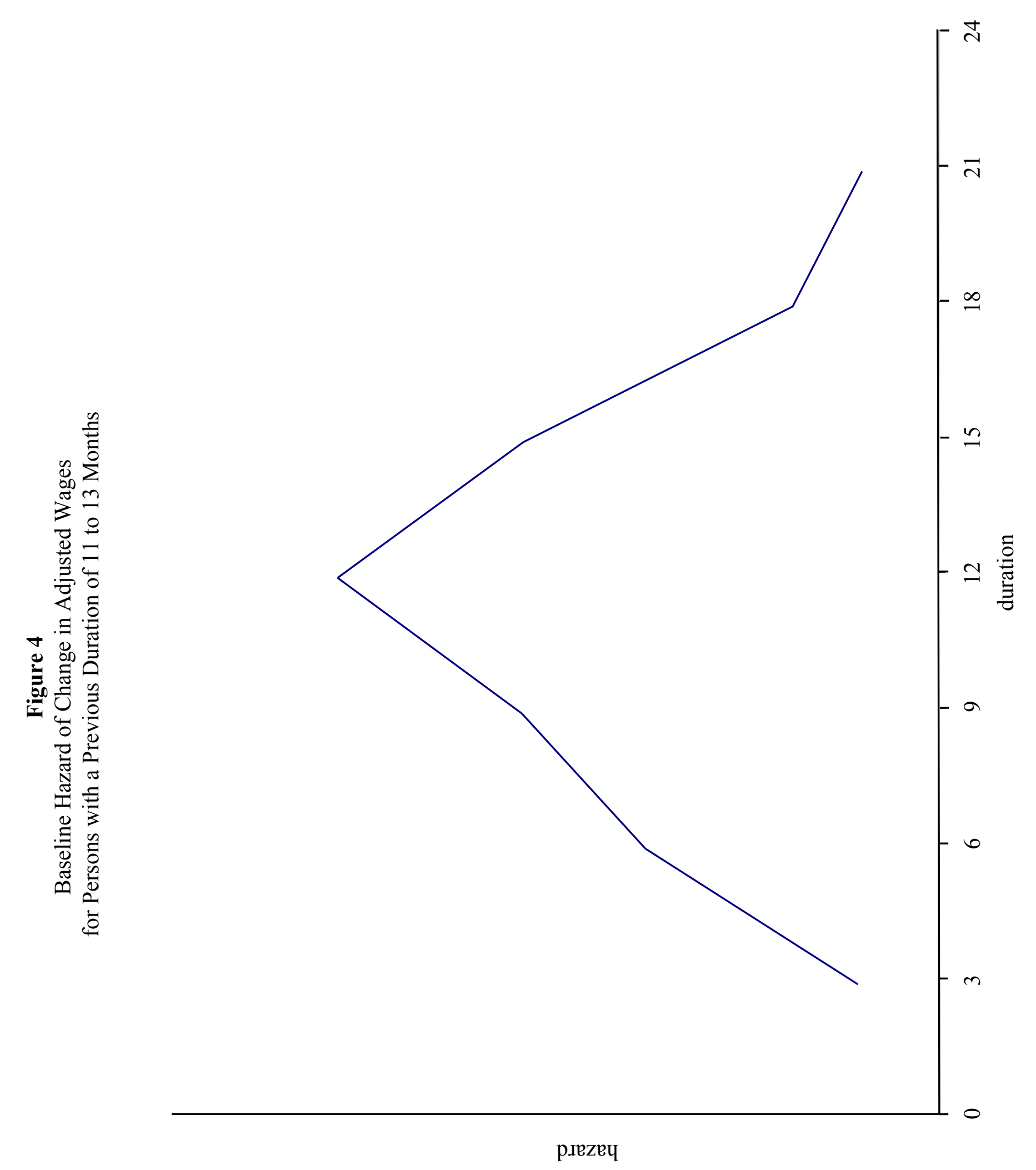


Table 1

Comparison of PSID and Specialized Studies

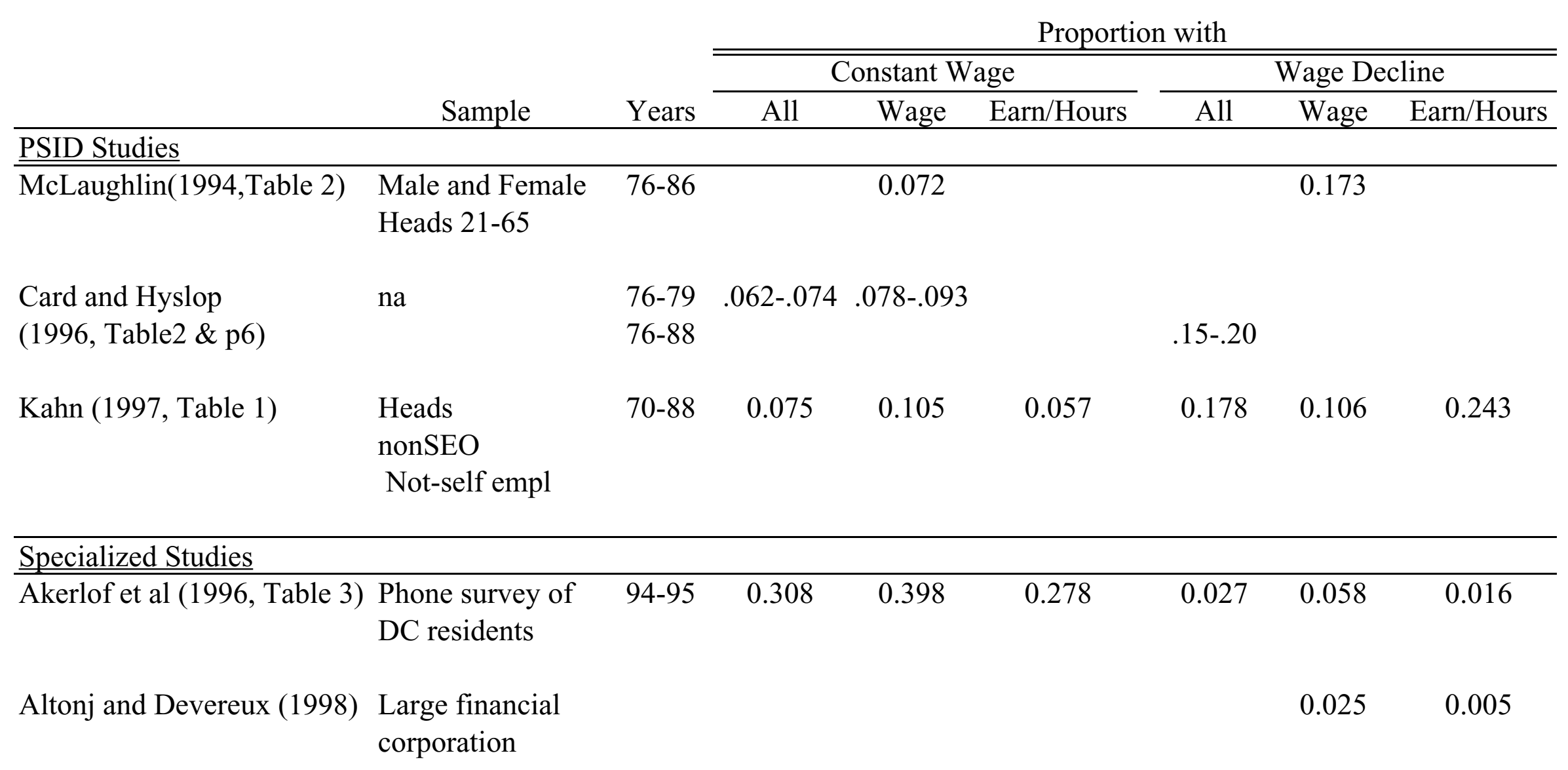




\section{Table 2}

\section{Descriptive Statistics}

\section{Males Females}

Persons

$\begin{array}{lcc}\text { Age } & 33.5 & 34.5 \\ \text { White Non-Hisp } & 0.751 & 0.769\end{array}$

Education

$\begin{array}{rcc}\text { LT High School } & 0.213 & 0.155 \\ \text { High School } & 0.517 & 0.499 \\ \text { Some College } & 0.206 & 0.246 \\ \text { College }+ & 0.068 & 0.101 \\ \text { Observations } & 21,406 & 21,940 \\ & & \\ \text { Mean 1995 wage } & \$ 11.69 & \$ 9.36 \\ \mathrm{P}_{10} & \$ 6.09 & \$ 5.12 \\ \mathrm{P}_{90} & \$ 18.21 & \$ 15.77 \\ \text { Yearly ln change } & 0.042 & 0.047\end{array}$

Jobs 


\section{Table 3}

Variance and Percentiles of Distributions of Yearly

Changes in Reported and Adjusted Wages

Males

Females

Reported Adjusted Reported Adjusted

\begin{tabular}{crrrr}
\hline \hline Variance & 0.033 & 0.013 & 0.029 & 0.013 \\
$\mathrm{P}_{01}$ & -0.336 & -0.182 & -0.349 & -0.175 \\
$\mathrm{P}_{05}$ & -0.091 & -0.009 & -0.087 & 0.000 \\
$\mathrm{P}_{25}$ & 0.000 & 0.000 & 0.000 & 0.000 \\
$\mathrm{P}_{50}$ & 0.025 & 0.000 & 0.034 & 0.000 \\
$\mathrm{P}_{75}$ & 0.074 & 0.057 & 0.080 & 0.068 \\
$\mathrm{P}_{95}$ & 0.223 & 0.191 & 0.222 & 0.189 \\
$\mathrm{P}_{99}$ & 0.457 & 0.358 & 0.480 & 0.369 \\
\hline
\end{tabular}




\section{Table 4}

Probability of Yearly Decline or Increase in Reported and Adjusted Wages

Males

Females

Reported Adjusted Reported Adjusted

\begin{tabular}{lllll}
\hline Decline & 0.157 & 0.051 & 0.136 & 0.043 \\
Constant & 0.251 & 0.537 & 0.228 & 0.492 \\
Increase & 0.591 & 0.412 & 0.636 & 0.465 \\
& 1.000 & 1.000 & 1.000 & 1.000 \\
\hline
\end{tabular}




\section{Table 5}

\section{Probability of Yearly Change}

in Adjusted Wages -- Correction for

Type I and Type II Errors
$\sigma_{\mathrm{u}}{ }^{2} / \sigma_{\mathrm{y}}{ }^{2}$
.20
.25
.30

Power
0.891
0.784
0.683

Male

Decline

Constant

Increase

Female

Decline

Constant

Increase
0.058

0.551

0.391

0.046

0.056

0.529

0.498

0.426
0.069

0.520

0.411

0.080

0.490

0.430 


\section{Table 6}

Distribution of Changes in Reported and Adjusted Wages Between Interviews

Males Females

Reported Adjusted Reported Adjusted

Decline

Constant

Increase
0.200

0.409

$\underline{0.391}$

1.000
0.020

0.858

$\underline{0.123}$

1.000
0.180

0.431

$\underline{0.400}$

1.000
0.015

0.849

$\underline{0.136}$

1.000 
Table 7

Cox Proportional Hazard Model of Decline in Nominal Wages

(1)

(2)

(3)

Males

Reported Adjusted Spurious

Age

Age Sq

White

(non-Hispanic)

Less than

High School

Some College

College

0.06
$[0.007]$

$-0.001$

[0.000]

$-0.108$

[0.023]

$-0.052$

[0.026]

0.082

[0.035]

0.058

[0.008]

$-0.001$

[0.000]

$-0.001$

[0.000]

0.064

[0.119]

$-0.116$

[0.024]

0.067

[0.124]

$-0.064$

[0.028]

$-0.008$

$-0.221$

$-0.001$

[0.143]

[0.027]

$-0.121$

0.049

$-0.125$

[0.041]

[0.187]

[0.044]

1.942

[1.234]

$-4.343$

2.231

[6.834]

[1.326]

57,205

29,355

54,595

Observations

29,355

(4)

(5)

(6)

Females

Adjusted

Spurious

0.031

0.03

0.033

[0.008]

[0.037]

[0.008]

0.000

0.000

0.000

[0.000]

[0.000]

[0.000]

$-0.167$

$-0.3$

$-0.148$

[0.024]

[0.115]

[0.026]

$-0.022$

0.101

$-0.02$

[0.032]

[0.143]

[0.034]

0.093

$-0.197$

0.108

[0.026]

[0.134]

[0.027]

0.138

$-0.045$

0.161

[0.034]

[0.173]

[0.035]

$-3.34$

$-23.579$

$-2.435$

[1.356] [7.364]

[1.439]

56,837

32,726

54,845 